\title{
Integrated Design and Evaluation of a Soil-Covering and Film-Mulching Device for Sugarcane Transverse Planters
}

\author{
$\mathrm{Ke} \mathrm{Li}^{1}$, Shizeng $\mathrm{Li}^{2}$, Xiao Teng ${ }^{1}$, Zhanglin Deng ${ }^{1}$, Wenbo Huang ${ }^{1}$, Fangfang Gan ${ }^{1}$ and Fanglan Ma ${ }^{1, *}$ \\ 1 College of Mechanical Engineering, Guangxi University, Nanning 530004, China; \\ 1811391032@st.gxu.edu.cn (K.L.); 1911391071@st.gxu.edu.cn (X.T.); 1811391008@st.gxu.edu.cn (Z.D.); \\ 1911391029@st.gxu.edu.cn (W.H.); 1911391018@st.gxu.edu.cn (F.G.) \\ 2 College of Traffic Engineering, Guangxi Technological College of Machinery and Electricity, Nanning 530007, \\ China; lsz@gxcme.edu.cn \\ * Correspondence: flma@gxu.edu.cn; Tel.: +86-156-7889-9955
}

check for

updates

Citation: Li, K.; Li, S.; Teng, X.; Deng, Z.; Huang, W.; Gan, F.; Ma, F. Integrated Design and Evaluation of a Soil-Covering and Film-Mulching Device for Sugarcane Transverse Planters. Agronomy 2021, 11, 1382. https://doi.org/10.3390/ agronomy 11071382

Academic Editor: Gareth T

C. Edwards

Received: 15 May 2021

Accepted: 3 July 2021

Published: 8 July 2021

Publisher's Note: MDPI stays neutral with regard to jurisdictional claims in published maps and institutional affiliations.

Copyright: (c) 2021 by the authors. Licensee MDPI, Basel, Switzerland. This article is an open access article distributed under the terms and conditions of the Creative Commons Attribution (CC BY) license (https:// creativecommons.org/licenses/by/ $4.0 /)$.

\begin{abstract}
To solve the problem that the covering device of sugarcane cannot be adequate for the agronomic standards of seed cane setts planting, a soil-covering and film-mulching device for sugarcane transverse planting was designed. The device includes a soil-covering part, soil-compacting part, and film-mulching part. Through theoretical analysis of key components, the factors affecting the cane seed covering quality for the device were obtained. A quadratic orthogonal rotation regression test was conducted by a homemade prototype to explore the effects of disk diameter, central distance, disk depth in soil, and dip angle on soil covering thickness. The results showed that the above factors all have an extremely significant effect on the soil covering thickness, and the effect degree of each factor from high to low is central distance, disk depth in soil, dip angle, and disk diameter within the range of test parameters. The optimal parameter combination, with the disk diameter, the dip angle, the central distance, the disk depth in soil, and the diameter of the soil-compacting wheel being $304.7 \mathrm{~mm}, 55.1^{\circ}, 386.5 \mathrm{~mm}, 32.4 \mathrm{~mm}$, and $300 \mathrm{~mm}$, respectively, was obtained by Design-Expert software and verified by comprehensive field tests. The results showed that the covering thickness is in the range of $94-111 \mathrm{~mm}$, the average value is $102.6 \mathrm{~mm}$, and the breakage rate is no more than $2.6 \%$. The emergence rate is $86.4 \%$, which is an improvement of $9.3 \%$ over that of a traditional covering device. The results suggested that the device can conform to the agricultural covering standard of sugarcane planting and provide a design basis for the application and popularization of the soil-covering and film-mulching device.
\end{abstract}

Keywords: sugarcane transverse planting; covering machinery; deep planting and shallow covering; mulching thickness

\section{Introduction}

Soil covering and film mulching are an important part of sugarcane planting. Some studies have shown that the covering quality of soil and film has enormously contributed to the germination and emergence rates of seed cane setts [1-3]. Appropriate thickness of soil covering and soil gap are conducive to cane seed budding [4,5]. If the soil covers thickly or compresses tightly, the resistance of breaking out soil for cane seed increases, which is harmful to budding [6]. On the contrary, if the thickness of soil covering is insufficient or the gap between the soil and cane seed is large, the setts may not absorb enough water and nutrients, which greatly decreases the emergence rate [7]. Furthermore, film mulching can improve soil temperature and reduce soil moisture evaporation, which is especially crucial for improving the emergence rate of seed cane setts [8-14]. Therefore, it is necessary to develop a soil-covering and film-mulching device conforming to the agronomic standards for sugarcane planting, and it has vital significance in improving the germination and emergence rate of sugarcane. 
The transverse sowing mode of precut seed cane setts has become a widely used planting pattern [15], because it has the advantages of low cane seed consumption, strong lodging resistance, and a high bud ratio and yield [16]. Its biggest advantage over other types of planters such as the whole cane rod type of real-time cutting is that it can realize wholly automatic operation, while others need human assistance to feed cane seeds $[17,18]$. However, at present, research on sugarcane transverse planting machines focuses on metering devices and furrow openers [19-21], while there is little research on soil-covering and filmmulching devices. Related research on mechanical devices of covering cultivation mainly focuses on wheat, rice, corn, and cotton, and the technology is relatively mature [22-26], but the structure of seed cane setts and agricultural standards of covering cultivation are very different from those of the above-mentioned crops. The agricultural requirements of sugarcane transverse planting are deep planting and shallow covering, and they include covering the soil first, then compacting the covered soil, and finally mulching film. Moreover, the furrow parameters and soil covering thickness are also very diverse [27]. Therefore, these covering machines cannot be applied to sugarcane planting. Han et al. [28] developed a covering device that realizes an automatic mulching film. Lu et al. [29] designed a sugarcane planter that can meet the functions of furrowing, sowing, fertilizing, and covering soil. Above all, these existing devices only meet the elementary covering soil or mulching film functions, but never integrate them, and they cannot cover seed cane setts according to the agronomic standards.

To improve the covering quality of cane seed and meet the covering agronomic standards of sugarcane transverse planting, a cane seed covering device that is suitable for a sugarcane transverse planter was designed. In this paper, the factors and laws affecting covering thickness were explored by the quadratic orthogonal rotation regression test, and its optimal parameter combination obtained by Design-Expert software was verified with the covering thickness and film breakage rate as indexes, which can provide a reference significance for the cane seed covering device.

\section{Materials and Methods}

\subsection{Agronomic Standards for Sugarcane Transverse Planting}

Guangxi has the largest sugarcane planting area in China, and its plantation area accounts for more than $60 \%$ of the national total [30]. Sugarcane transverse planting is an innovative planting pattern that has been widely used in Guangxi in recent years (Figure 1), which requires that the cane seeds be planted deeply and covered shallowly. The planting parameters are shown in Table 1. The furrowing depth is $300 \mathrm{~mm}$, the furrowing width is $400 \mathrm{~mm}$, the planting depth is $200 \mathrm{~mm}$, the soil covering thickness is $90-120 \mathrm{~mm}$, the film thickness is $0.6 \mathrm{~mm}$, and its breakage rate is less than $10 \%$. The pressure exerted on soil is suitable, $30-50 \mathrm{kPa}$, and the working speed of the sugarcane planter generally matches the first gear forward speed of the tractor.

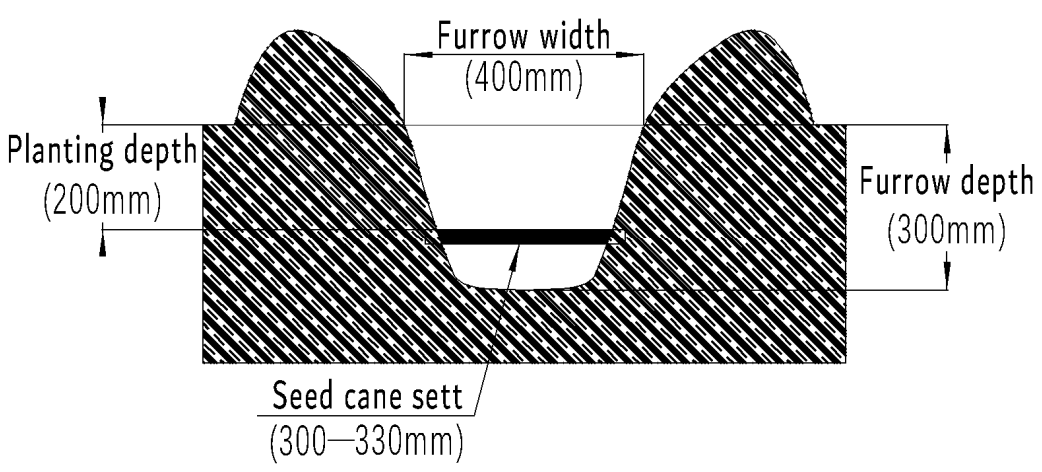

Figure 1. Transverse planting of a seed cane sett. 
Table 1. Agronomic standards for sugarcane transverse planting.

\begin{tabular}{cc}
\hline Technical Index & Parameters \\
\hline Furrow depth, $\mathrm{mm}$ & 300 \\
Furrow width, mm & 400 \\
Planting depth, $\mathrm{mm}$ & 200 \\
Soil covering thickness, $\mathrm{mm}$ & $90-120$ \\
The pressure exerted on soil, $\mathrm{kPa}$ & $30-50$ \\
Forward speed of sugarcane planter, $\mathrm{km} / \mathrm{h}$ & About 2.8 \\
Film & Width 600, thickness 0.6 \\
Breakage rate, $\%$ & $<10$ \\
\hline
\end{tabular}

\subsection{Overall Structure of the Soil-Covering and Film-Mulching Device}

The soil-covering and film-mulching device is installed at the end of the planter, and its lifting on the planter is controlled by a hydraulic system (Figure 2). The workflow of the planter is furrowing, fertilizing, sowing, soil covering, and film mulching. The soil-covering and film-mulching device is mainly composed of a soil-covering disk, soil-compacting wheel, roller of paving film, film-pressing wheel, auxiliary wheel, and soil-scraping disk and adjusting device (Figure 3).

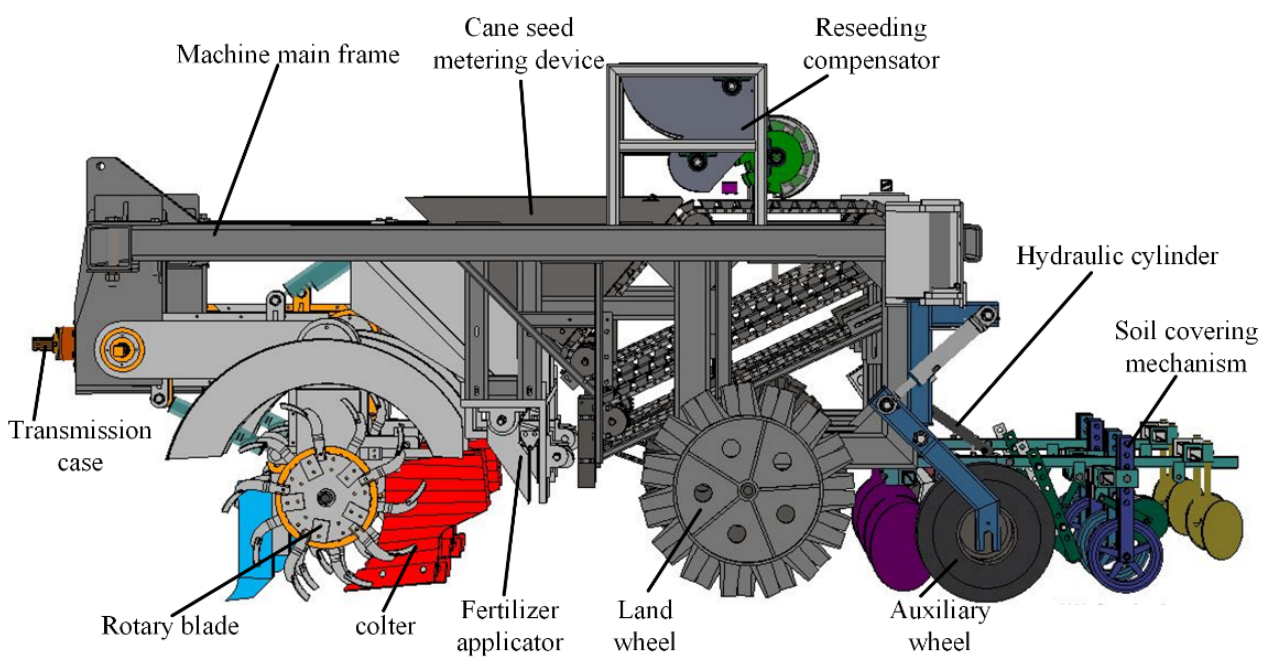

Figure 2. Overall structure of the transverse planter.

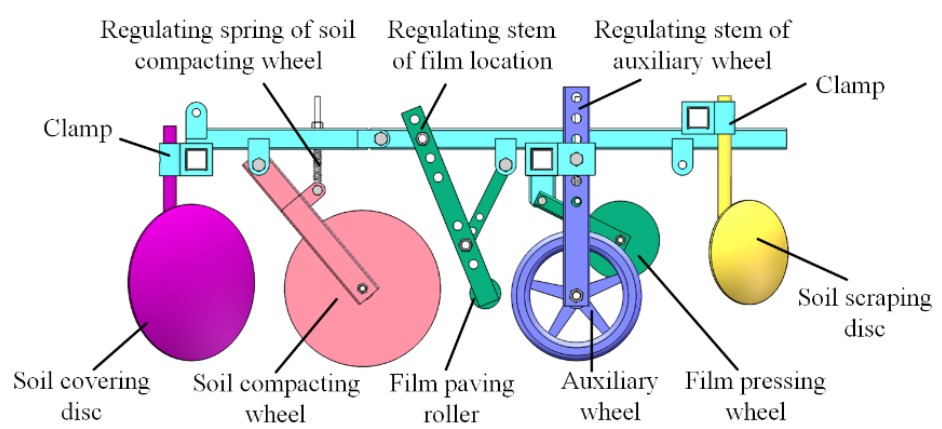

(a)

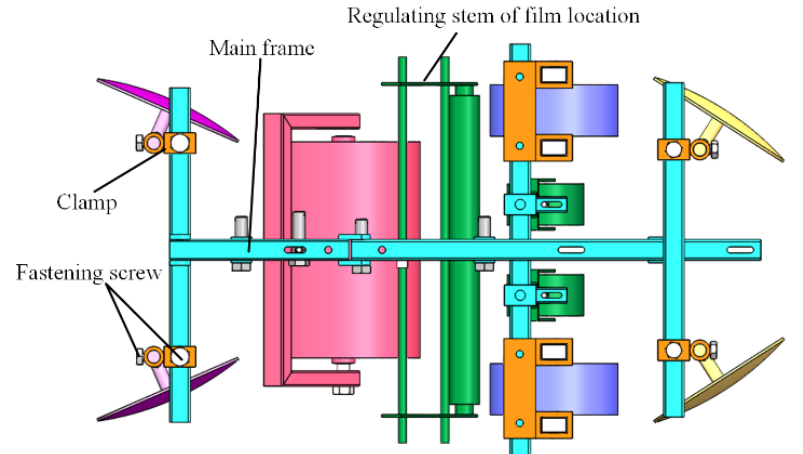

(b)

Figure 3. (a) Side view of the covering device. (b) Top view of the covering device.

\subsection{Working Principle}

When the planter moves forward, the rotary blade and colter plow out a furrow, and the metering device sows cane seeds into the furrow, and then the covering device 
covers the cane seed in the furrow with soil. The working process of the covering device is followed by covering soil, compacting the covered soil, mulching film, and covering soil to the film surface.

Covering soil: The covering disks are in contact with the soil. When the planter moves forward, the disk forms a relative motion to the soil, and the touched soil flows to the furrow center along the disk surface. The disks are symmetrically distributed at a certain dip angle (Figure 3b), and the dip angle, depth in soil, and central distance of the two are controlled by the clamp.

Compacting the covered soil: The soil-compacting wheel rolls over the covered soil surface and makes the covered soil compact. The degree of compaction mainly depends on the gravity of the soil-pressing wheel. The soil surface becomes flat after compaction, which can effectively reduce the breakage rate of the film.

Mulching film: The film is installed on the film-paving roller, and there are bearings in the film-paving roller. Before mulching film, workers pull out a section of the film, and then, the film-pressing wheel and auxiliary wheels hold down this section of the film. When the planter moves forward, the pressed section pulls the film-paving roller rotation, which causes the film to be stretched out continuously. The stretched-out film sticks to the compacted soil surface because of the film-pressing wheel and auxiliary wheel.

Covering soil on the film surface: After mulching the film, the soil-scraping disks cover both sides of the paved film with slight soil to prevent winds from blowing the film away.

\subsection{Design of the Soil-Covering Part}

The soil-covering part is one of the key components of the covering device, and it is composed of a soil-covering disk and a clamp (Figure 4). The clamp can regulate the disk depth in soil, the central distance of the two disks, and the dip angle with the forward direction of planter motion. There are scales marked on the cylindrical sleeve. The fastening screws tighten the connecting rod of the disk.

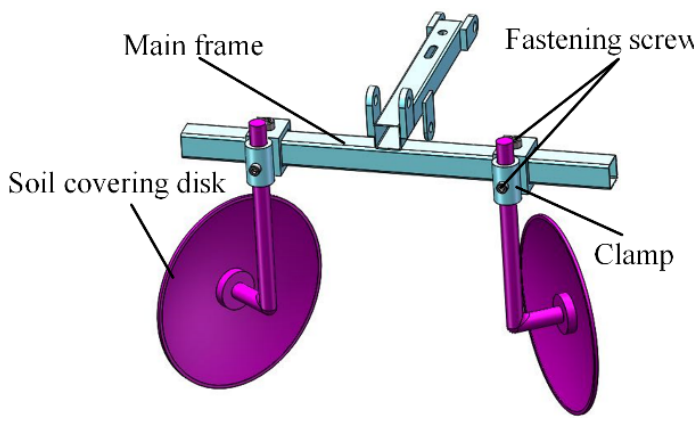

(a)

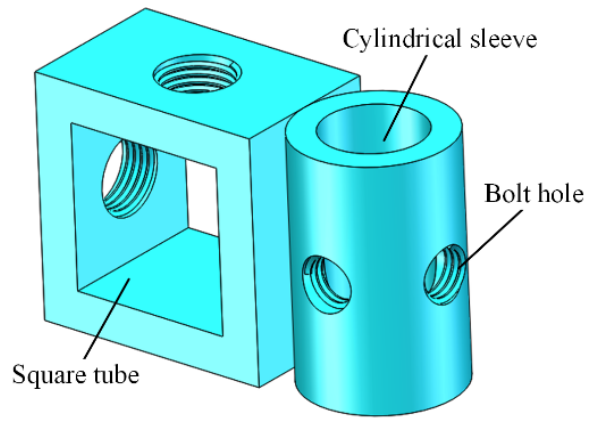

(b)

Figure 4. (a) The soil-covering part. (b) Clamp.

The amount of soil covering is the key index for the soil covering device. Therefore, the contact area between covering disk and soil and its movement trajectory were analyzed. The disk is concave, and its side profile is nearly $\mathrm{V}$ shaped, and the V-shaped angle $\beta$ is decided by the curvature radius $R$ (Figure 5). It is assumed that the soil area is $S$, and $S$ meets the formulas as follows:

$$
\left\{\begin{array}{l}
\varphi=\arccos \frac{h}{r} \\
S=\frac{\frac{\pi r^{2}}{180^{\circ}} \arccos \frac{h}{r}-h \sqrt{r^{2}-h^{2}}}{\cos \beta}
\end{array}\right.
$$

where $r$ is the radius of the soil-covering disk $(\mathrm{mm}), h$ is the distance from the disk center to the soil surface $(\mathrm{mm}), \varphi$ is the central angle of disk $\left(^{\circ}\right)$, and $\beta$ is the V-shaped angle $\left(^{\circ}\right)$. 


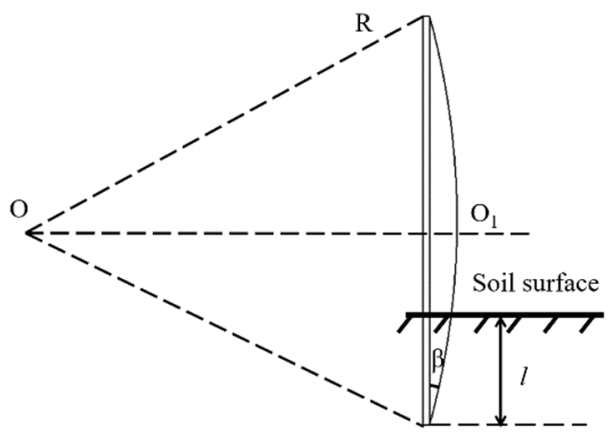

(a) Side view of the disk

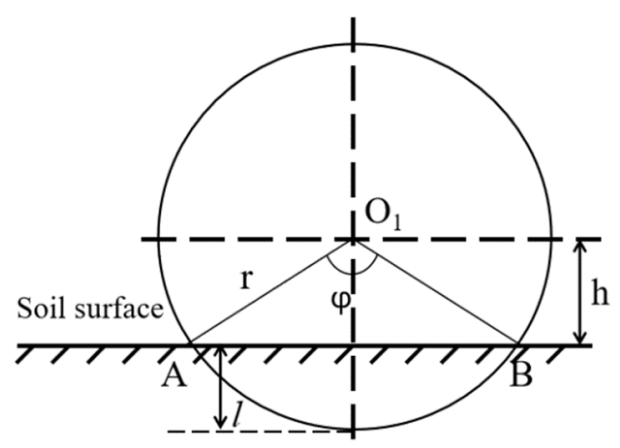

(b) Front view of the disk

Figure 5. The contact area between covering disk and soil.

According to Formula (1), the soil contact area is related to the disk diameter, Vshaped angle, and the depth of the disk in soil. To find out the related factors about the amount of soil covering, the movement trajectory of contact soil particles was analyzed (Figure 6). Because the soil humidity is low in its planting, the adhesion between soil particles is negligible. According to the dynamic analysis, the following formulas can be obtained:

$$
\left\{\begin{array}{l}
m \frac{d^{2} x}{d t^{2}}=F_{n} \sin \theta+F_{f} \sin (\omega t) \cos \theta \\
m \frac{d^{2} y}{d t^{2}}=F_{n} \cos \theta+F_{f} \cos (\omega t) \sin \theta \\
m \frac{d^{2} z}{d t^{2}}=F_{f} \sin (\omega t) \\
F_{f}=\mu F_{n} \\
\mu=\tan \alpha \\
\omega=\frac{\lambda v \cos \theta}{r}
\end{array}\right.
$$

where $m$ is the weight of the soil particle $(\mathrm{kg}), F_{n}$ is the acting force of soil particles perpendicular to the disk plane $(\mathrm{N}), F_{f}$ is the friction between the particle and the disk $(\mathrm{N})$, $\theta$ is the dip angle between the disk surface and the forward direction of planter motion $\left(^{\circ}\right)$, $\mu$ is the dynamic friction factor between soil and disk, $\alpha$ is the friction angle between soil particles $\left({ }^{\circ}\right), \omega$ is the angular speed of disk rotation ( $\left.\mathrm{rad} / \mathrm{s}\right), \lambda$ is the speed coefficient of angular speed, and $v$ is the walking speed of the sugarcane planter $(\mathrm{m} / \mathrm{s})$.

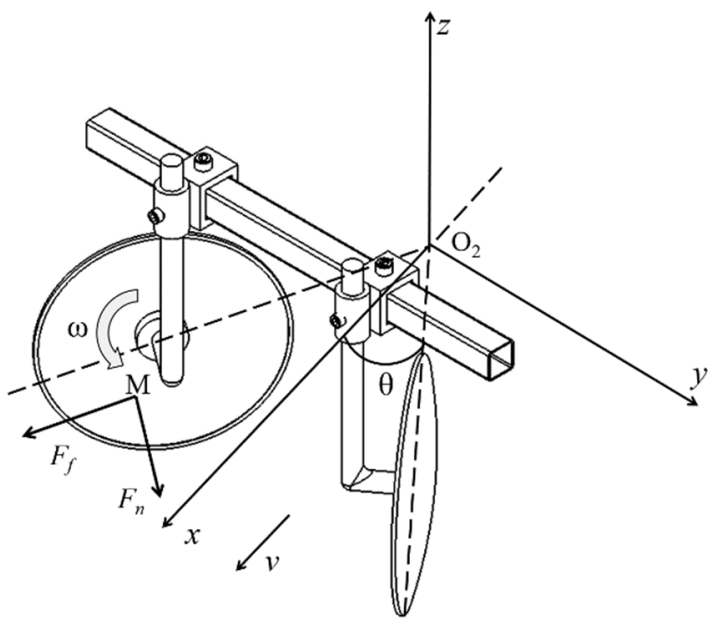

Figure 6. The dynamic analysis of a soil particle.

The displacement of the soil particle in the $x, y$, and $z$ directions is obtained by Formula (2) integrated twice: 


$$
\left\{\begin{array}{l}
x=\frac{1}{m}\left[\frac{F_{n} \sin \theta}{2} t^{2}\right]-\frac{F_{f} r^{2} \cos ^{3} \theta}{\lambda^{2} v^{2}} \sin \left(\frac{\lambda v \cos \theta t}{r}\right)+C_{0} t+C_{1} \\
y=\frac{1}{m}\left[\frac{F_{n} \cos \theta}{2} t^{2}\right]-\frac{F_{f} r^{2} \sin ^{3} \theta}{\lambda^{2} v^{2}} \cos \left(\frac{\lambda v \cos \theta t}{r}\right)+C_{2} t+C_{3} \\
z=\frac{1}{m}\left[-\frac{F_{f} r^{2} \cos ^{3} \theta}{\lambda^{2} v^{2}} \sin \left(\frac{\lambda v \cos \theta t}{r}\right)+C_{4} t+C_{5}\right]
\end{array}\right.
$$

where $C_{0}, C_{1}, C_{2}, C_{3}, C_{4}$, and $C_{5}$ are integration constants.

Based on Formulas (1)-(3), the walking speed of planter, the disk diameter, the Vshaped angle, the dip angle, and the depth of the disk in soil are related to the amount of soil covering. The central distance of the two disks also has an influence on the amount of soil covering, because there is a furrow between the two disks. If the distance is large, the soil will not flow back to the furrow, which results in insufficient soil covering. If the distance is small, the covering disk will scrape the seed cane setts in the furrow. The above factors about the amount of soil covering were analyzed. During planting operation, the sugarcane planter moves forward at first gear speed of the tractor, and the walking speed is basically constant. For disk diameter, according to the empirical formula, the disk diameter should meet the condition

$$
d=a k
$$

where $d$ is the disk diameter ( $\mathrm{mm}), a$ is thickness of soil covering $(\mathrm{mm})$, and $k$ is the ratio of diameter to thickness.

The central distance $l$ needs to meet the following conditions:

$$
\left\{\begin{array}{l}
l_{\max }<l \\
l-2 \sqrt{r_{\min ^{2}}{ }^{2} h_{\min ^{2}}} \sin \theta_{\min }<l_{1}
\end{array}\right.
$$

where $l_{\max }$ is the maximum length of cane seed $(\mathrm{mm}), l_{1}$ is the furrow width $(\mathrm{mm}), r_{\min }$ is the minimum diameter of the soil-covering disk $(\mathrm{mm}), h_{\min }$ is the minimum distance from the disk center to the soil surface $(\mathrm{mm})$, and $\theta_{\min }$ is the minimum dip angle $\left(^{\circ}\right)$.

According to the Agricultural Machinery Designing Handbook [31], the value of $k$ is generally 2-2.5. The sugarcane planting area in Guangxi is dominated by red earth [32], and based on the actual measurements of our research group, the soil covering thickness decreases by about $20-30 \mathrm{~mm}$ at a pressure of $30-50 \mathrm{kPa}$. Therefore, the thickness of soil covering before being compacted is $110-150 \mathrm{~mm}$. Therefore, the disk diameter is 220-375 mm. In view of the topographic fluctuations and measurement errors, the disk diameter was selected as $200-400 \mathrm{~mm}$ in the tests. According to the design standard of the concave disk, the disk radius $R$ of curvature, which decides the V-shaped angle $\beta$, is a constant value of $550 \mathrm{~mm}$ within this disk diameter range. To make the soil flow to the furrow and avoid excessive force on the disk, according to the previous tests of our research group, the range of dip angles was set as 30-70 , and the disk depth in the soil is between $30 \%$ and $45 \%$ of the disk radius. Thus, according to Formula (5), the central distance $l$ ranges from 320 to $471.4 \mathrm{~mm}$, and the central distance was selected as 350-450 $\mathrm{mm}$ in the tests to avoid scraping the cane seed. Above all, the variable factors that affect the amount of soil covering are disk diameter, dip angle, disk depth in soil, and central distance.

\subsection{Design of the Soil-Compacting Wheel}

To smooth the soil surface after compaction, the soil-compacting wheel is cylindrical, and the material is Q235 steel. The soil compaction is an important index for the soilcompacting wheel, and the pressure exerted on the soil is $30-50 \mathrm{kPa}$; therefore, the soil compressive stress under the soil-compacting wheel was analyzed (Figure 7).

The touched area between soil and soil-compacting wheel $S_{2}$ can be expressed as:

$$
\left\{\begin{array}{l}
\gamma_{0}=\arcsin \left(\frac{r_{1}-h_{1}}{r_{1}}\right) \\
S_{2}=\frac{\pi r_{1} \gamma_{0}}{180^{\circ}} L
\end{array}\right.
$$


where $\gamma_{0}$ is the central angle of the soil-compacting wheel corresponding to the touched soil area $\left({ }^{\circ}\right) ; r_{1}$ is the radius of the soil-pressing wheel $(\mathrm{mm})$, and $L$ is the width of the soil-pressing wheel (mm).

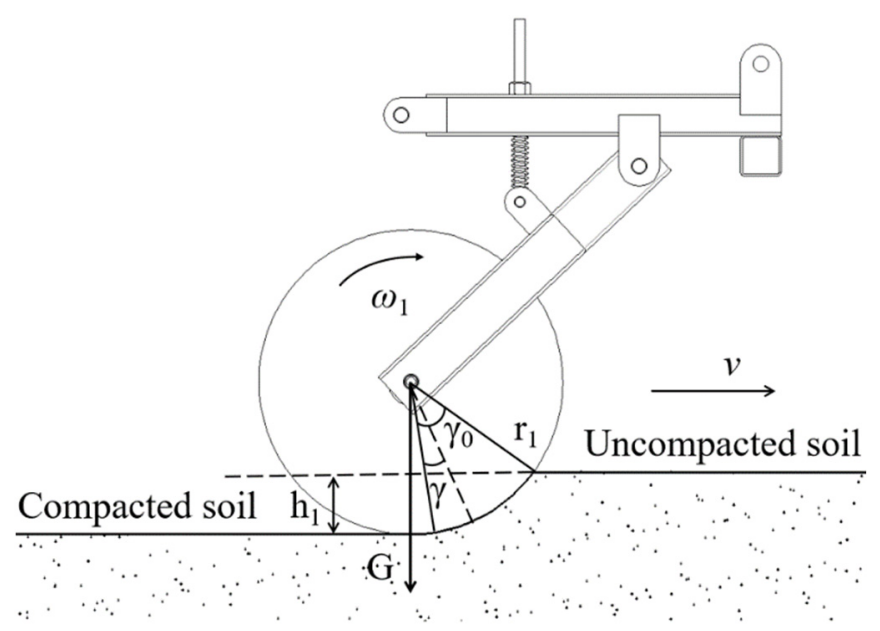

Figure 7. The process of soil compacting.

The soil compressive stress is mainly provided by the gravity of the wheel itself, and it can be expressed as:

$$
\sigma=\frac{180^{\circ} \rho g \int_{0}^{\gamma_{0}} \cos \gamma d \gamma}{\gamma_{0}}
$$

where $\sigma$ is soil compressive stress $(\mathrm{kPa}), \rho$ is the material density of the soil-pressing wheel $\left(\mathrm{kg} / \mathrm{m}^{3}\right), g$ is gravitational acceleration $\left(\mathrm{m} / \mathrm{s}^{2}\right)$, and $\gamma$ is the variate of $\gamma_{0}\left({ }^{\circ}\right)$.

The soil compressive stress $\sigma$ should meet the condition:

$$
30 \mathrm{kPa}<1000 \frac{180^{\circ} \rho g \int_{0}^{\arcsin \left(\frac{r_{1}-h_{1}}{r_{1}}\right)} \cos \gamma d \gamma}{\arcsin \left(\frac{r_{1}-h_{1}}{r_{1}}\right)}<50 \mathrm{kPa}
$$

To prevent the soil-compacting wheel from heaping soil during operations, according to the Agricultural Machinery Designing Handbook, the soil-compacting wheel should also meet the condition:

$$
r_{1} \geq \frac{W_{p}}{(F+G) f_{1}}
$$

where $W_{p}$ is the friction torque in the shaft sleeve $(\mathrm{N} / \mathrm{mm}), F$ is the external force excepted gravity (N), $G$ is the gravity of the soil-pressing wheel (N), and $f_{1}$ is the friction coefficient between soil and wheel material $(\mathrm{N})$.

According to Formulas (8) and (9), the diameter of the soil-compacting wheel is nearly 200-400 mm. Considering the topographic fluctuations, the wheel diameter was selected as $300 \mathrm{~mm}$. The cane seed in the furrow is transverse (Figure 1). To ensure that the covered soil directly above the cane seed can be compacted, the width of the soil-pressing wheel should be larger than the length of the cane seed setts, and the width of the soil-compacting wheel is designed to be $350 \mathrm{~mm}$.

The simulation dynamics of the above-designed soil-pressing wheel was carried out by EDEM, a discrete element simulation software developed by DEM Solutions company, Edinburgh, UK. The simulation parameters [33-35] are shown in Table 2, and the variation of soil pressure, simulated by the software EDEM is shown in Figure $8 \mathrm{~b}$. The pressure data can be exported from the EDEM post-processing module. The simulation results show that there is no heap soil in the compacting process, and the soil pressure of the pressing wheel on soil is about $33-48 \mathrm{kPa}$. 
Table 2. The simulation parameters of the compacting process.

\begin{tabular}{cc}
\hline Parameters & Numerical Value \\
\hline Poisson's ratio of soil $^{\prime}$ & 0.35 \\
Poisson's ratio of soil-pressing wheel & 0.28 \\
Shear modulus of soil, MPa & 10.5 \\
Soil density, $\mathrm{kg} / \mathrm{m}^{3}$ & 1.256 \\
Frictional angle, $^{\circ}$ & 15.7 \\
Dynamic friction factor $^{3}$ of soil-pressing wheel, $\mathrm{kg} / \mathrm{m}^{3}$ & 0.21 \\
Density & 7.85 \\
Shear modulus of soil-pressing wheel, $\mathrm{MPa}$ & 79,000 \\
Soil collision coefficient of restitution & 0.1 \\
\hline
\end{tabular}

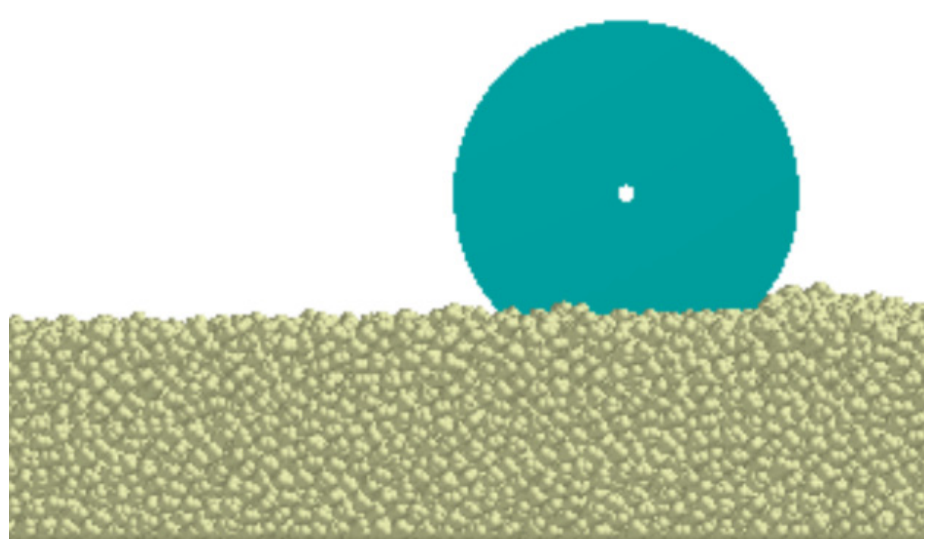

(a)

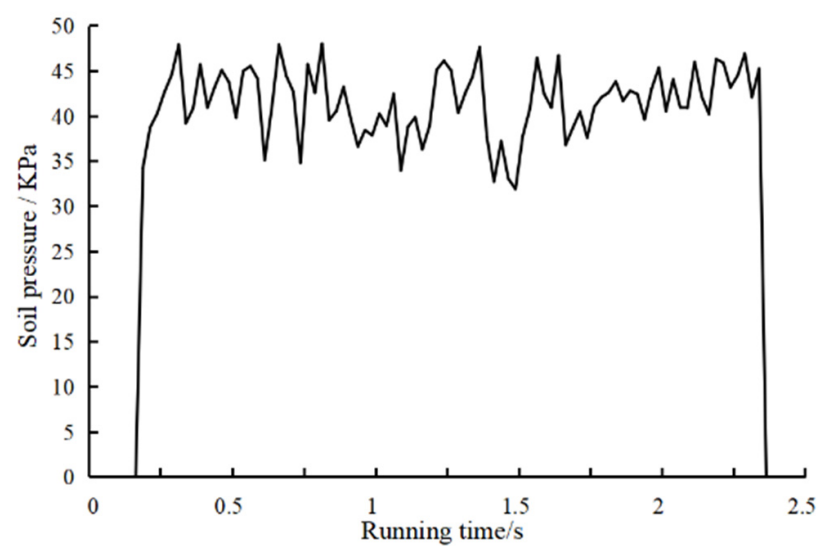

(b)

Figure 8. (a) Compacting simulation process. (b) Soil pressure in compacting process.

\subsection{Design of the Mulching Film Part}

The structure of the mulching film part is shown in Figure 9. The film is installed on the film-paving roller, and the location of the film-paving roller is adjusted by the regulating stem and the regulating screw. The nuts on the regulating screw can regulate the used film width. Before paving film, a section of the film is pulled out and pressed under the film-pressing wheel. The function of the film-pressing wheel is to press the film down and stretch it out continuously. The height of the auxiliary wheel can be altered by the auxiliary plate to improve the balance of the paving film. The soil-scraping disk can cover a thin layer of soil on the paved film to prevent the mulching film from being blown away.

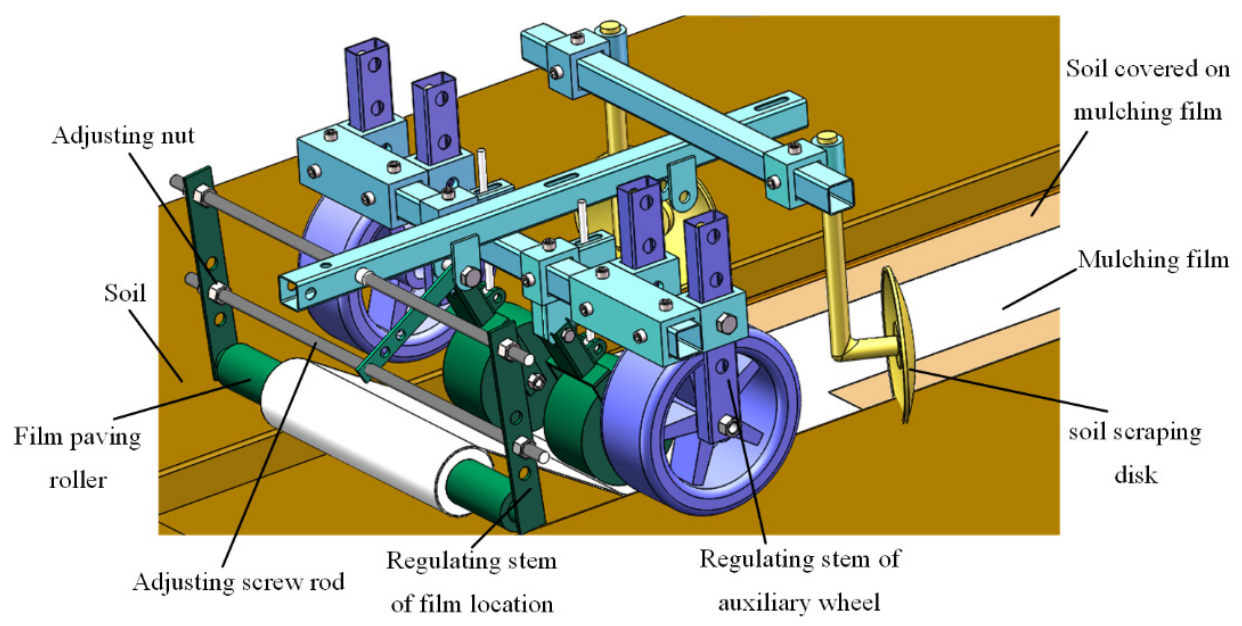

Figure 9. The structure of the mulching film part. 


\section{Results}

To explore the effect of the above variables on the soil covering thickness and find out the optimal parameter combination that accords with the agronomic standards, a quadratic orthogonal rotation regression test was conducted by using a homemade prototype.

\subsection{Test Condition}

The test was carried out in the experimental field of Guangxi University, and the instruments and equipment used in the test included a Renault 1804 tractor, a sugarcane transverse planter, a homemade prototype of a soil-covering and film-mulching device, and tape measure (Figure 10). The soil type is red earth, and its moisture content is $17.18 \%$, volume-weight is $1.204-1.256 \mathrm{~g} / \mathrm{cm}^{3}$, and the friction coefficient between soil and steel is 0.34 . In this test, ROC22 double-bud seed cane setts were selected. This variety currently has a large planting area in Guangxi.
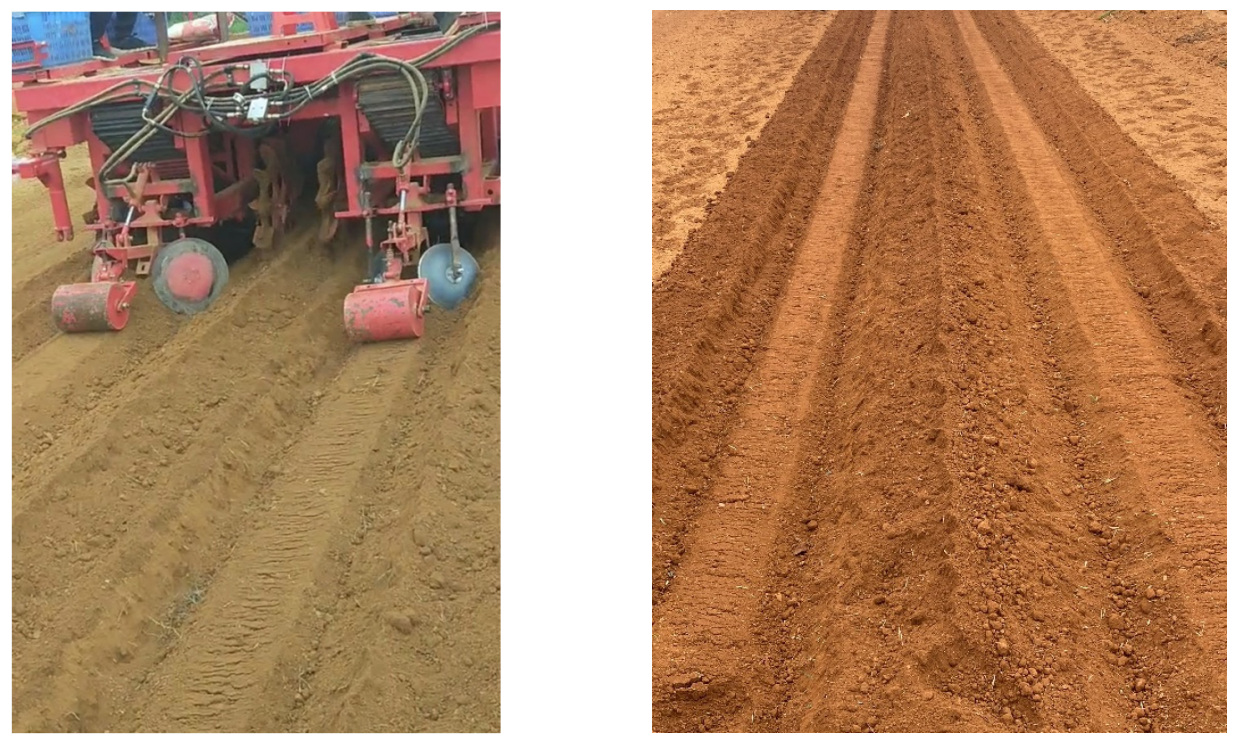

Figure 10. The field test of soil thickness.

\subsection{Trial Protocol}

According to the purpose of the test, a quadratic orthogonal rotation regression test was conducted with the soil covering thickness after compaction as index, and the disk diameter, dip angle, disk depth in soil, and central distance as the test factors. The test factor coding is shown in Table 3. Before the test, the soil-covering part and the soilpressing wheel were reserved, and the film-mulching part was removed. The compaction is expressed by the difference value of soil thickness before and after compaction. The thickness is measured by tape measure. Holes in the cane seed sowing site were dug, and the distance from the cane seed surface to the compaction plane, that is, the soil covering thickness, was measured. The planter moved $50 \mathrm{~m}$ in each group, and the sowing interval was about $330 \mathrm{~mm}$. Each group was randomly counted covering a thickness of 20 sowing sites to obtain the average value. The results are shown in Table 4.

\subsection{Statistical Analysis}

Due to the influence of various factors, the obtained data show fluctuations, and the causes of fluctuations fall into two categories. One is caused by different experimental conditions; another is caused by random error. Variance analysis (ANOVA) can be used to test the significance of difference in sample mean, and the influencing factors on research results were determined by analyzing the contribution of the variations ( $F$-value) from different sources to the total variation. To explore the significant influencing factors on the soil covering thickness and the interaction between factors, ANOVA was conducted 
on the test results using Microsoft Excel software. To find out the optimal parameter combination of the above factors, the response surface methodology (RSM) was used to fit the functional relationship between the influencing factors and the soil covering thickness. RSM is an optimization method, and it can show the functional relationship by using graphics technology, which can help us to easily find out the optimal conditions. RSM can provide a function prediction model between multiple factors and target values by establishing multiple linear regression formula, which is an effective method to solve multivariate problems. Design-Expert is the most widely used software in response surface analysis, because its data processing results are relatively reliable. Therefore, in this study, the Design-Expert software was used for response surface analysis.

Table 3. Test factor coding.

\begin{tabular}{ccccc}
\hline & \multicolumn{4}{c}{ Natural Variables $\boldsymbol{x}_{\mathbf{j}}$} \\
\cline { 2 - 5 } Canonical Variables $z_{\mathbf{j}}$ & $\begin{array}{c}\text { Disk } \\
\text { Diameter } \boldsymbol{x}_{\mathbf{1}} \\
(\mathbf{m m})\end{array}$ & $\begin{array}{c}\text { Dip Angle } \\
\left.\boldsymbol{x}_{\mathbf{2}} \mathbf{(}^{\circ}\right)\end{array}$ & $\begin{array}{c}\text { Central } \\
\text { Distance } \boldsymbol{x}_{\mathbf{3}} \\
(\mathbf{m m})\end{array}$ & $\begin{array}{c}\text { Disk Depth in } \\
\left.\text { Soil } \boldsymbol{x}_{\mathbf{4}} \mathbf{( m m}\right)\end{array}$ \\
\hline Upper asterisk arm $\gamma$ & 400 & 70 & 450 & 90 \\
Upper level (1) & 359.5 & 61.9 & 429.7 & 77.8 \\
Zero level (0) & 300 & 50 & 400 & 60 \\
Lower level (-1) & 240.5 & 38.1 & 370.3 & 42.2 \\
Lower asterisk arm $\gamma$ & 200 & 30 & 350 & 30 \\
Variable interval & 59.5 & 11.9 & 29.7 & 17.8 \\
\hline
\end{tabular}

Table 4. The results of the quadratic orthogonal rotation regression test.

\begin{tabular}{cccccc}
\hline Site Number & $\boldsymbol{x}_{\mathbf{1}}(\mathbf{m m})$ & $\boldsymbol{x}_{\mathbf{2}}\left(^{\circ}\right)$ & $\boldsymbol{x}_{\mathbf{3}} \mathbf{( \mathbf { m m } )}$ & $\boldsymbol{x}_{\mathbf{4}} \mathbf{( \mathbf { m m } )}$ & Soil Thickness $\mathbf{y} \mathbf{( \mathbf { m m } )}$ \\
\hline 1 & 240.6 & 61.9 & 429.7 & 77.8 & 118.5 \\
2 & 300.0 & 50.0 & 400.0 & 60.0 & 113.1 \\
3 & 400.0 & 50.0 & 400.0 & 60.0 & 125.1 \\
4 & 300.0 & 30.0 & 400.0 & 60.0 & 65.3 \\
5 & 240.6 & 61.9 & 370.3 & 77.8 & 121.4 \\
6 & 300.0 & 50.0 & 400.0 & 60.0 & 162.8 \\
7 & 359.5 & 38.1 & 370.3 & 77.8 & 112.3 \\
8 & 300.0 & 50.0 & 400.0 & 60.0 & 162.7 \\
9 & 300.0 & 50.0 & 350.0 & 60.0 & 68.1 \\
10 & 240.6 & 38.1 & 429.7 & 42.2 & 113.4 \\
11 & 300.0 & 50.0 & 400.0 & 60.0 & 132.8 \\
12 & 359.5 & 61.9 & 370.1 & 42.2 & 154.5 \\
13 & 300.0 & 50.0 & 400.0 & 60.0 & 101.2 \\
14 & 300.0 & 50.0 & 400.0 & 90.0 & 126.8 \\
15 & 240.6 & 38.1 & 370.1 & 42.2 & 83.0 \\
16 & 300.0 & 70.0 & 400.0 & 60.0 & 88.2 \\
17 & 200.0 & 50.0 & 400.0 & 60.0 & 114.5 \\
18 & 300.0 & 50.0 & 400.0 & 30.0 & 98.9 \\
19 & 300.0 & 50.0 & 400.0 & 60.0 & 115.2 \\
20 & 359.5 & 38.1 & 429.7 & 77.8 & 99.2 \\
21 & 300.0 & 50.0 & 450.0 & 60.0 & \\
22 & 300.0 & 50.0 & 400.0 & 60.0 & 42.0 \\
23 & 359.5 & 61.9 & 429.7 & 42.2 & \\
\hline
\end{tabular}

\subsection{Result Analysis}

The variance analysis results are shown in Table 5.

According to the analysis of variance results, for a $95 \%$ confidence interval, the $p$ values for $x_{1}, x_{2}, x_{3}$, and $x_{4}$ and the pairwise interactions of $x_{1} x_{2}, x_{1} x_{3}, x_{1} x_{3}$, and $x_{2} x_{3}$ were far less than 0.01 , which has an extremely significant effect on the thickness of soil covering. The $p$-value for $x_{3} x_{4}$ is 0.0212 , which has a significant effect on the thickness of soil covering. 
The $F$-values for disk diameter $x_{1}$, dip angle $x_{2}$, central distance $x_{3}$, and disk depth in soil $x_{4}$ were $267.13,568.01,1291.80$, and 661.14 , respectively. Therefore, the effect order of the four factors on the experimental index was central distance, disk depth in soil, dip angle, and disk diameter. The response surface analysis (Figure 11) for the test factors affecting the index was carried out by the Design-Expert software.

Table 5. Variance analysis of the test results.

\begin{tabular}{ccccccc}
\hline Source & Adj. SS & Freedom & Adj. MS & F-Value & $p$-Value & Significance \\
\hline Model & $14,662.34$ & 14 & 1047.31 & 314.90 & $<0.0001$ & $* * *$ \\
$x_{1}$ & 888.44 & 1 & 888.44 & 267.13 & $<0.0001$ & $* * *$ \\
$x_{2}$ & 1889.12 & 1 & 1889.12 & 568.01 & $<0.0001$ & $* * *$ \\
$x_{3}$ & 4296.37 & 1 & 4296.37 & 1291.80 & $<0.0001$ & $* * *$ \\
$x_{4}$ & 2198.89 & 1 & 2198.89 & 661.14 & $<0.0001$ & $* * *$ \\
$x_{1} x_{2}$ & 92.39 & 1 & 92.39 & 27.78 & 0.0008 & $* * *$ \\
$x_{1} x_{3}$ & 271.96 & 1 & 271.96 & 81.77 & $<0.0001$ & $* * *$ \\
$x_{1} x_{4}$ & 563.82 & 1 & 563.82 & 169.53 & $<0.0001$ & $* * *$ \\
$x_{2} x_{3}$ & 473.55 & 1 & 473.55 & 142.38 & $<0.0001$ & $* * *$ \\
$x_{2} x_{4}$ & 0.020 & 1 & 0.020 & $5.932 \times$ & 0.9405 & \\
$x_{3} x_{4}$ & 27.20 & 1 & 27.20 & 8.18 & 0.0212 & $* *$ \\
$x_{1}{ }^{2}$ & 171.03 & 1 & 171.03 & 51.42 & $<0.0001$ & $* * *$ \\
$x_{2}{ }^{2}$ & 594.25 & 1 & 594.25 & 178.68 & $<0.0001$ & $* * *$ \\
$x_{3}^{2}$ & 601.08 & 1 & 601.08 & 180.73 & $<0.0001$ & $* * *$ \\
$x_{4}^{2}$ & 127.59 & 1 & 127.59 & 38.36 & 0.0003 & $* * *$ \\
Residual error & 26.61 & 8 & 3.33 & & & \\
Lack of fit & 14.09 & 2 & 7.04 & 3.38 & 0.1042 & \\
Error & 12.52 & 6 & 2.09 & & & \\
Total & $14,688.94$ & 22 & & & & \\
\hline
\end{tabular}

Note: $p<0.01$ indicates extremely significant ${ }^{* * *} ; 0.01 \leq p \leq 0.05$ indicates significant ${ }^{* *}$; and $p>0.05$ indicates not significant.

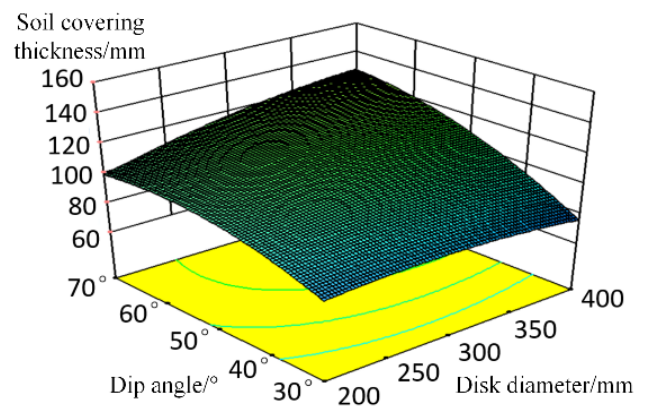

(a)

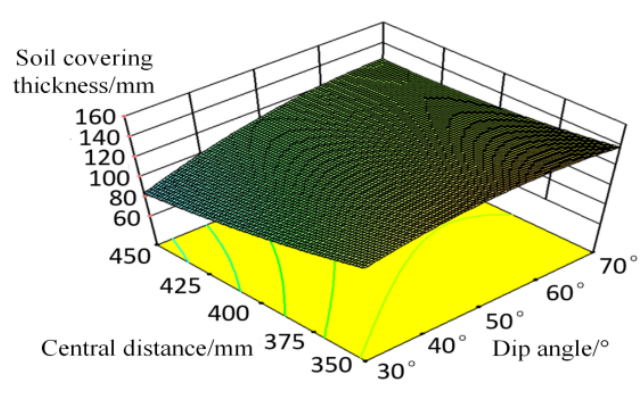

(c)

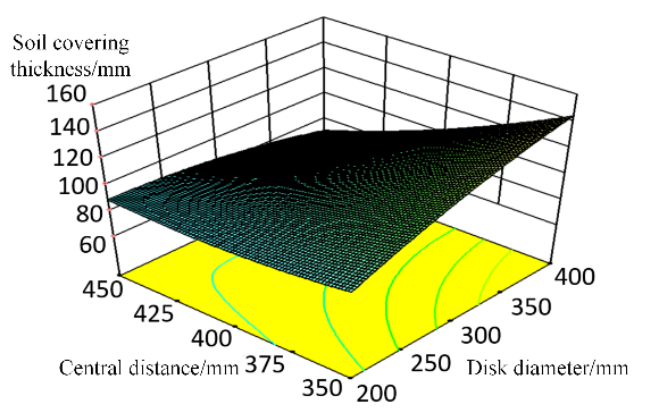

(b)

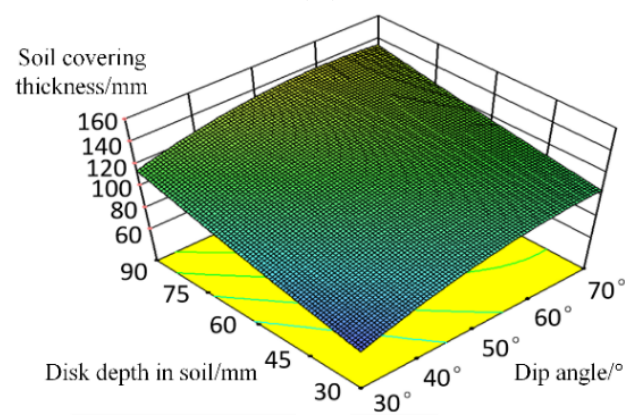

(d)

Figure 11. Cont. 


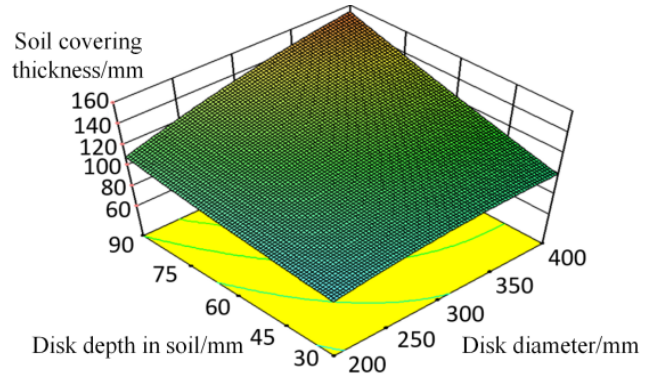

(e)

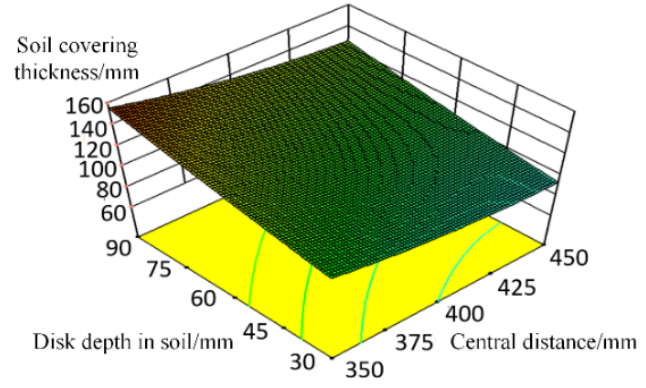

(f)

Figure 11. The analysis results of response surface between (a) dip angle and disk diameter, (b) central distance and disk diameter, (c) central distance and dip angle, (d) disk depth in soil and dip angle, (e) disk depth in soil and disk diameter, and (f) disk depth in soil and central distance.

According to the results of the response surface analysis, the soil covering thickness increases with the increase in disk diameter, disk depth in soil, and dip angle, but decreases with the increase in central distance. When the disk diameter and the disk depth increase, the soil-touched area is larger, more soil flows back to the center of furrow, and the covering thickness increases. When the dip angle increases, the distance of the soil flowing back to the furrow along the disk surface becomes shorter, and the amount of soil flowing towards the furrow center increases. When the central distance increases, the distance of the soil flowing back to the furrow becomes larger. It is difficult for the soil to flow back to the furrow because of the friction between the soil particles, and the covering thickness decreases. The regression formula between each related factor and covering thickness $Y_{1}$ was obtained:

$Y_{1}=113.3+12.53 x_{1}+18.27 x_{2}-17.77 x_{3}+19.67 x_{4}-5.85 x_{1} x_{3}+13.04 x_{1} x_{4}+7.72 x_{2} x_{3}-3.28 x_{1}^{2}-6.12 x_{2}^{2}+6.16 x_{3}^{2}$

Considering the installed error and fluctuation of the terrain, the median covering thickness of $105 \mathrm{~mm}$ was selected as the optimal target parameter. The above regression Formula (10) was selected as objective function, and the central distance $l$ was more than $380 \mathrm{~mm}$ to completely avoid scratching the cane seeds. The parameter combinations of the above four factors (Table 6) were obtained by Design-Expert.

Table 6. Variance analysis of the test results.

\begin{tabular}{cccccc}
\hline Serial Number & $x_{\mathbf{1}}(\mathbf{m m})$ & $x_{\mathbf{2}}\left({ }^{\circ}\right)$ & $x_{\mathbf{3}}(\mathbf{m m})$ & $x_{\mathbf{4}}(\mathbf{m m})$ & $y_{\mathbf{1}}(\mathbf{m m})$ \\
\hline 1 & 284.7 & 54.4 & 418.3 & 55.4 & 105 \\
2 & 304.7 & 55.1 & 386.5 & 32.4 & 105 \\
3 & 249.7 & 49.3 & 381.7 & 35.1 & 105 \\
4 & 266.7 & 47.4 & 381.4 & 40 & 105 \\
5 & 271.6 & 68.2 & 415.8 & 42.8 & 105 \\
\hline
\end{tabular}

\subsection{Comprehensive Test of Field Validation}

The optimal combination was selected from the above parameter combinations with the disk resistance as the dominant factor, and the combination was as follows: disk diameter, $304.7 \mathrm{~mm}$; dip angle, 55.1 ${ }^{\circ}$; central distance, $386.5 \mathrm{~mm}$; and depth in soil, $32.4 \mathrm{~mm}$. To test the effect of soil covering, compaction, and film mulching, a verification test was carried out on the soil-covering and film-mulching device (Figure 12). The soil thickness and breakage rate of the film were selected as the test indexes. The planter moved $50 \mathrm{~m}$, and randomly counted covering thickness of 10 sowing sites. The test results are shown in Table 7 . The breakage rate of film is defined as:

$$
\alpha=\frac{L_{1}}{L}
$$


where $L_{1}$ is the length of the broken mulching film $(\mathrm{m})$ and $L$ is the total length of the paved film (m).
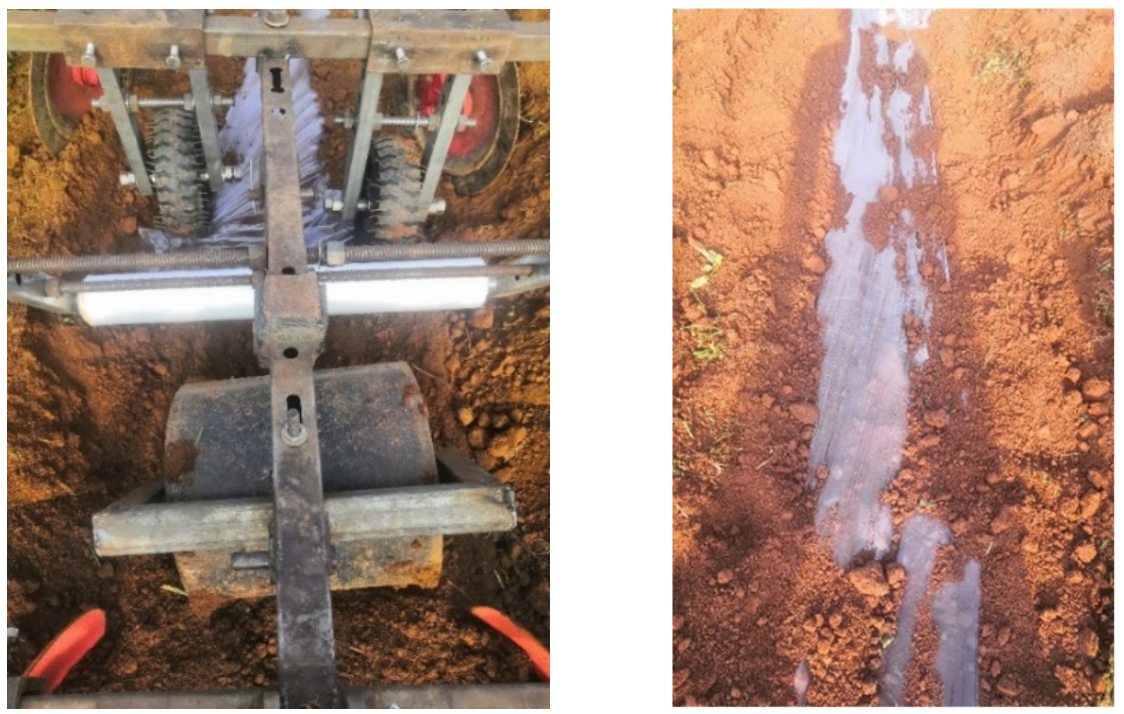

Figure 12. The comprehensive test in the field.

Table 7. The results of the verification test.

\begin{tabular}{|c|c|c|c|c|c|c|c|c|c|c|c|}
\hline Index & 1 & 2 & 3 & 4 & 5 & 6 & 7 & 8 & 9 & 10 & Average \\
\hline Soil thickness after compaction(mm) & 102 & 108 & 111 & 99 & 104 & 105 & 102 & 94 & 97 & 104 & 102.6 \\
\hline Total broken length $L_{1}(\mathrm{~m})$ & \multicolumn{11}{|c|}{1.27} \\
\hline Total breakage rate $\alpha(\%)$ & \multicolumn{11}{|c|}{2.54} \\
\hline Emergence rate of the device $(\%)$ & \multicolumn{11}{|c|}{86.4} \\
\hline Emergence rate of other existing devices (\%) & \multicolumn{11}{|c|}{77.1} \\
\hline
\end{tabular}

The emergence rates of cane seeds planted by the covering device and planted by other existing covering devices were statistically analyzed after the cane seed broke through the soil (Figure 13). Each measurement randomly counted the emergence rate of cane seeds as $10 \mathrm{~m}$ units, and the sowing space was $0.33 \mathrm{~m}$. There was no mis-seeding because artificial reseeding was carried out during the planting. In total, 1000 setts were counted for each kind of emergence rate, and compared. The results are shown in Table 7.

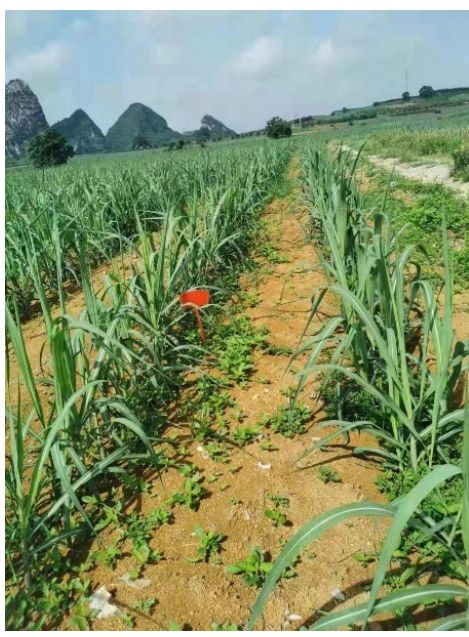

(a)

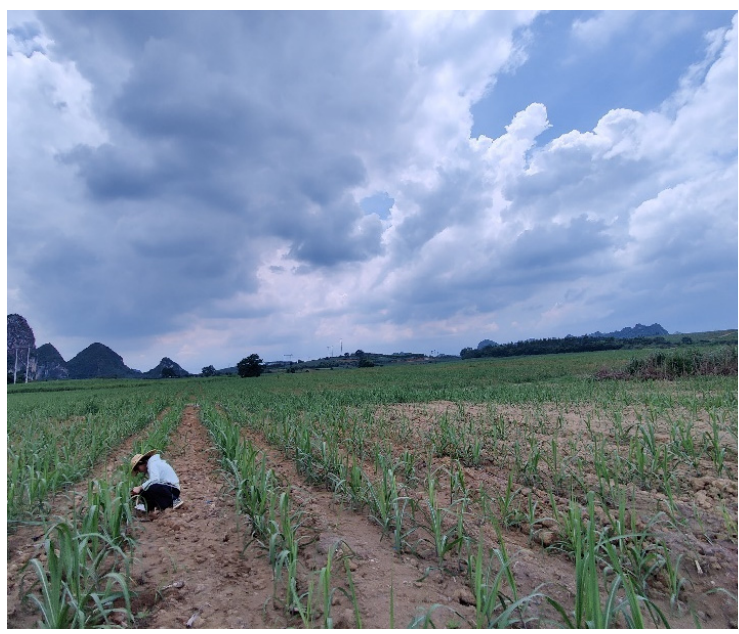

(b)

Figure 13. (a) Cane seed planted by this device. (b) Cane seed planted by other existing devices. 
According to the verification test results, the maximum thickness after compaction is $112 \mathrm{~mm}$, the minimum is $94 \mathrm{~mm}$, and the average is $102.6 \mathrm{~mm}$, and there was no heap soil for the soil-pressing wheel. The breakage rate of the film is $2.54 \%$. The breakage rate decreased by more than $45 \%$ compared with the existing covering devices that only cover soil [28], and the emergence rate improved by $9.3 \%$. The results show that the soil thickness is in the normal range. The device can meet the agronomic covering requirements of sugarcane transverse planting, and the standard covering can improve the emergence rate effectively for cane seed.

\section{Discussion}

The emergence rate of cane seed is one of the effective indexes to infer the yield of sugarcane. The test study shows that covering cultivation has a great influence on the emergence rate of cane seed. According to the covering thickness of $102.6 \mathrm{~mm}$, soil surface compaction of $30-50 \mathrm{kPa}$, and mulching film of $0.6 \mathrm{~mm}$, the emergence rate is $86.4 \%$, which is $9.3 \%$ higher than that of traditional devices covered with random soil thickness only. This is the same as the study results of the emergence mechanism of cane seed. In this paper, a covering device was designed, which integrates the functions of soil covering and compaction, and film mulching. The related factors on soil thickness and a mathematical model of soil thickness with its related factors were obtained by regression analysis. The field shows that the actual soil covering thickness is basically consistent with that of the model predicted. The study results can provide an important reference for the popularization of the cane seed covering device. However, this study did not explore the effect of different compaction degrees, soil thicknesses, and types of films on the cane seed emergence rate, and the optimal covering parameters need to be further explored and verified.

\section{Conclusions}

In this paper, a covering device for cane seed was designed. The device is mainly composed of a soil-covering disk, soil-compacting wheel, film-mulching part, and soilscraping disk and adjusting device. Through a theoretical analysis of the soil-covering disk and soil-pressing wheel, the related factors of soil covering thickness and its parameters range were obtained, and parameters of the soil-pressing wheel were selected.

The parameters of the soil-pressing wheel were analyzed by EDEM software. The simulation results showed that the pressure exerted on soil is in the range of $33-48 \mathrm{kPa}$, which is suitable for the compaction requirement, and there is no heap soil. The effects of the soil-covering disk on soil covering thickness were explored by the quadratic orthogonal rotation regression test, the effect law mathematical model, and the optimal parameter combination was obtained by Design-Expert. The regression test showed that the disk diameter, disk depth in soil, dip angle, and central distance have an extremely significant effect on the soil covering thickness, and the effect degree of each factor from high to low is central distance, disk depth in soil, dip angle, and disk diameter within the range of the test parameters. The effect law is that the covering thickness increases with an increase in disk depth in soil, dip angle, and disk diameter, and decreases with the central distance.

In the optimal combination that the moving speed of the planter, the disk diameter, the dip angle, the central distance, the disk depth in soil, and the diameter of the soilcompacting wheel are $2.8 \mathrm{~km} / \mathrm{h}, 304.7 \mathrm{~mm}, 55.1^{\circ}, 386.5 \mathrm{~mm}, 32.4 \mathrm{~mm}$, and $300 \mathrm{~mm}$, respectively, the soil covering thickness is in the range of $94-112 \mathrm{~mm}$, which meets the standard of $90-120 \mathrm{~mm}$, and the breakage rate of film is less than $2.6 \%$. The emergence rate is $86.4 \%$, which is an improvement of $9.3 \%$. The device test results suggested that the device is designed reasonably, and it can contribute to the emergence rate of cane seed. The analysis method can be suitable for the standard covering design of cane seed. This paper can provide new design ideas and data support for sugarcane covering machines. 
Author Contributions: Conceptualization: K.L.; data collection analysis and writing of the original draft preparation: K.L. and Z.D.; data measurement: X.T., W.H., and F.G.; writing and reviewing: F.M., S.L. All authors have read and agreed to the published version of the manuscript.

Funding: This research was funded by Project of Guangxi Science and Technology (grant number AB18281016), Project of State Key Laboratory for Conservation and Utilization of Subtropical (grant number SKLCUSA-b201706), and the Innovation Project of Guangxi Graduate Education (grant number YCSW2021024).

Institutional Review Board Statement: Not applicable.

Informed Consent Statement: Not applicable.

Data Availability Statement: Data reported within the article.

Acknowledgments: The authors wish to thank Li Shangping, Hou Yi, and Luo Xiaohu for help in prototype manufacturing and field testing.

Conflicts of Interest: The authors declare no conflict of interest.

\section{References}

1. Qiu, L.H.; Fan, Y.G.; Luo, H.M.; Huang, X.; Lu, R.F.; Yang, R.Z.; Wu, J.M.; Li, Y.R. Advances of regulation study on tillering formation and stem forming from available tillers in sugarcane. Plant Physiol. J. 2018, 54, 192-202.

2. Yan, W.Z.; Fang, X.F.; Zhu, Q.Z.; Liang, T.; Luo, Y.W. Preliminary Study on Mulching Technology of Sugarcane Variety 05-51 in Menghai County. Sugar Crop. China 2018, 40, 38-39.

3. Zhang, H.; Luo, J.; Yuan, Z.N.; Gao, S.J.; Yang, Y.Y.; Lin, Z.L. Agronomic techniques to sugarcane mechanical seeding. J. Anhui Agric. Sci. 2007, 17, 5126-5200.

4. Luo, J.; Lin, Z.L.; Li, S.Y.; Que, Y.X.; Zhang, C.F.; Yang, Z.Q.; Yao, K.C.; Feng, J.F.; Chen, J.F.; Zhang, H. Effects of different soil improvement measures on soil physicochemical properties and microbial community structures in mechanically compacted acidified sugarcane field. Acta Agron. Sin. 2020, 46, 596-613.

5. Shukla, S.K.; Jaiswal, V.P.; Lalan, S.; Pathak, A.D.; Akhilesh, K.S.; Gupta, R.; Awasthi, S.K.; Asha, G.; Adil, Z.; Raghvendra, T. Sugarcane Yield Using Minimum Tillage Technology Through Subsoiling: Beneficial Impact on Soil Compaction, Carbon Conservation and Activity of Soil Enzymes. Sugar Tech 2020, 22, 1-20. [CrossRef]

6. Wellingthon, D.S.G.J.; Etienne, D.I.C.D.M.; Cezar, F.A.; Camila, V.V.F.; Zigomar, M.D.S. Prediction of soil stresses and compaction due to agricultural machines in sugarcane cultivation systems with and without crop rotation. Sci. Total Environ. 2019, 681, 424-434.

7. Gao, X.X.; Liu, G.Y.; Liu, S.C.; Guo, J.W. Research Progress in the Effect of Mechanical Compaction on Soil and Root Growth in Sugarcane Fields. Chin. J. Trop. Agric. 2020, 40, 29-34.

8. Farah, A.H.; Al-Ghobari, H.M.; Zin El-Abedin, T.K.; Alrasasimah, M.S.; El-Shafei, A.A. Impact of Partial Root Drying and Soil Mulching on Squash Yield and Water Use Efficiency in Arid. Agronomy 2021, 11, 706. [CrossRef]

9. Barrett-Lennard, E.G.; Munir, R.; Mulvany, D.; Williamson, L.; Riethmuller, G.; Wesley, C.; Hall, D. Micro-Water Harvesting and Soil Amendment Increase Grain Yields of Barley on a Heavy-Textured Alkaline Sodic Soil in a Rainfed Mediterranean Environment. Agronomy 2021, 11, 713. [CrossRef]

10. Bi, J.Y.; Wang, X.F.; Zhu, D.L. Effect of plastic-film mulch on crop yield. Trans. Chin. Soc. Agric. Eng. 2008, 11, $172-175$.

11. Xu, S.N.; Wu, J.M.; Huang, X.; Xie, J.L.; Luo, Y.W.; Liang, T.; Huang, J.Y.; Li, Y.R. Effects of different plastic films mulching on soil temperature and moisture, and growth and yield of sugarcane. J. South. Agric. 2014, 45, 2137-2142.

12. Huang, C.; Jiang, L.; Chen, X.; Wang, F.T.; An, P.L. Research on the effects of plastic film mulching and seedling transplanting on crop yield and water and heat resource utilization. J. China Agric. Univ. 2018, 23, 1-2.

13. Li, Y.Z.; Yang, J.B.; Shi, Z.; Pan, W.H.; Liao, Y.C.; Li, T.; Qin, X.L. Response of root traits to plastic film mulch and its effects on yield. Soil Tillage Res. 2021, 209, 104930. [CrossRef]

14. Wang, Y.; Sun, W.; Zhang, Y. Simulation of Soil Temperature Field of Potato Ridge Sowing with White Film Mulch and Soil Covering the Seed Band. Am. J. Potato Res. 2020, 97, 405-419. [CrossRef]

15. Liu, Q.T.; Mo, J.L.; Li, Y.H.; Qu, Y.G. Current situation of sugarcane planter and its key technical issues in china. Sugarcane Canesugar 2011, 5, 52-58.

16. Li, S.P.; Huang, Z.X.; Zhang, W.; Wang, M.P.; Mo, H.N. Experiments and Design on Single-rolled Seed-sowing System of pre-seed-cutting Sugarcane Planters with Wide and Narrow Row Spacing. Trans. Chin. Soc. Agric. Mach. 2020, 51, $113-121$.

17. Khwantri, S.; Chaloemthoi, C.; Kamwilaisak, K.; Kasemsiri, P.; Chaun-Udom, S.; Taira, E. Effect of metering device arrangement to discharge consistency of sugarcane billet planter. Eng. Agric. Environ. Food 2018, 11, 139-144.

18. Kumar, M.; Dogra, B.; Sanghera, G.S.; Manes, G.S. Modification and Evaluation of Commercially Available Sugarcane Trench Planter for Its Application Under Punjab Conditions. Sugar Tech 2019, 21, 586-595. [CrossRef]

19. Thienyaem, T.; Saengprachatanarug, K.; Wongpichet, S.; Eizo, T.; Thongrak, P. The influence of the metering device arrangement to the diskharging consistency of the sugarcane billet planter. Adv. Mater. Res. 2014, 931, 1561-1567. [CrossRef] 
20. Taghinezhad, J.; Alimardani, R.; Jafari, A. Design, development and evaluation of a new mechanism for sugarcane metering device using analytical hierarchy method and response surface methodology. Sugar Tech 2015, 17, 258-265. [CrossRef]

21. Singh, S.; Tripathi, A.; Singh, A.K. Effect of Furrow Opener Design, Furrow Depth, Operating Speed on Soil Characteristics, Draft and Germination of Sugarcane. Sugar Tech 2017, 19, 476-484. [CrossRef]

22. Tang, X.P.; Zhao, W.Y.; Dai, F.; Yang, Z. Design and manufacture of an integrated machine to spread membrane covering soil and seeding for dry land wheat. Agric. Res. Arid. Areas 2013, 31, 248-251.

23. Zhao, L.J.; He, D.; Zhou, F.J. Parameter optimization and test on soil-covering mechanism of 2BF-1400 rice mulching film seeder machine. Trans. Chin. Soc. Agric. Eng. 2015, 31, 21-26.

24. Guo, H.; Chen, Z.; Jia, H.L.; Zheng, T.Z.; Wang, G.; Wang, Q. Design and experiment of soil-covering and soil-compacting device with cone-shaped structure of wheel. Trans. Chin. Soc. Agric. Eng. 2017, 33, 56-65.

25. Dai, F.; Song, X.F.; Zhao, W.Y.; Wei, W.C.; Zhang, F.W.; Ma, H.J. Design and Experiment of Operation Machine for Filming and Covering Soil on Tiny Ridges. Trans. Chin. Soc. Agric. Mach. 2021, 51, 97-105.

26. Sun, W.; Simionescu, P.A. Parameter Analysis and Field Tests of a Double Crank Multi-Rod under Plastic-Film Hill-Drop Mechanism Potato Planter. Am. J. Potato Res. 2020, 97, 256-264. [CrossRef]

27. Zhong, J.Q.; Tao, L.M.; Li, S.P.; Ma, F.L.; Chen, Y.L. Design and Evaluation of a Novel Transversal Double-bud Sugarcane Planter with Seed Pre-cutting. Sugar Tech 2021, 1-10, in press.

28. Han, J.; Wen, S.; Liu, Q.T.; Wu, J.Y.; Xu, J.C.; Wu, J.R.; Ou, C.H.; Yan, W.H. Design and test of pre-cutting type sugarcane planter. J. South China Agric. Univ. 2019, 40, 109-118.

29. Lu, Q.Y.; Li, R.; Zheng, Z.X.; Hong, S.J.; Wang, S.N. Design and Prototype Test of a New Type Sugarcane Planter. J. Agric. Mech. Res. 2020, 42, 79-84.

30. Zhang, C.X.; Lu, H. Current situation and suggestiongs of sugarcane harvest mechanization in Guang Xi. Trans. Chin. Soc. Agric. Eng. 2019, 9, 5-9. [CrossRef]

31. Chinese Academy of Agricultural Mechanization Sciences. Agricultural Machinery Designing Handbook; China Agricultural Science and Technology Press: Beijing, China, 2007; p. 251.

32. Ma, F.L.; Li, K.; Luo, X.H.; Teng, X.; Mo, D.Q. Study of Different Soils on the Load Pressure of Sugarcane Cutting. J. Agric. Mech. Res. 2021, 44, 165-173.

33. Tian, D.Y.; Liu, J.D.; Jiao, H.B. Parameters Optimization and Analysis for Covering Disc Based on Discrete Element Modeling. J. Agric. Mech. Res. 2018, 40, 16-22.

34. Song, L.P.; Yang, X.H.; Li, Q. Simulation study on precision seeding disc covering device based on SPH mesh less method. J. Chin. Agric. Mech. 2016, 37, 29-32.

35. Chang, Z. Theoretical and Numerical Research on Granular Mechanics of Soils. Master's Thesis, Tsinghua University, Beijing, China, 2008. 